\title{
Tecer ninhos, ousar voos: a produção de multiplicidades nos territórios de usuários de um Centro de Atenção Psicossocial
}

\author{
Weaving nests, daring to fly: production of multiplicities \\ in the territories of users of Psychosocial Care Centers
}

Nathália Ferreira de Souza e Silva (https://orcid.org/0000-0002-1085-4603) ${ }^{1}$

${ }^{1}$ Centro de Atenção Psicossocial, Secretaria Municipal de Saúde, Prefeitura Municipal de Suzano. Rua Baruel 501, Centro. 08675-000 Suzano SP Brasil. nathaliafs9@gmail.com

\begin{abstract}
In the light of new challenges posed to processes of deinstitutionalization by Brazil's mental health reform, this study explores the production of existential territories in the city by recording the experiences of users of a psychosocial care center in São Paulo. Using methods based on social cartography, including the creation of affective maps and accompanying participants on routes around the city, it was possible to understand how participants weave multiplicities of living territories and networks throughout their itineraries, breaking free from places instituted by the asylum logic and cementing the principles of deinstitutionalization in the micropolitics of their everyday lives. During this process, the participants'experiences stimulated reflections on the kind of cities we want to build, collectively reinventing urban territories, making them more sensitive and permeable to instituting forces and creating new ways of living together and producing differences. At the same time, they stimulate reflection on how these singular experiences of the city can be incorporated into and enhance the therapeutic itineraries of clinical practices based on the "logic of territory".
\end{abstract}

Key words Mental health, Deinstitutionalization, Mental health services, Cities, Public health
Resumo Frente às novas questões que se colocam, a partir da Reforma Psiquiátrica Brasileira, para os processos de desinstitucionalização da loucura no campo da saúde mental, esta pesquisa se debruça sobre os processos de produção de territórios existenciais na cidade, a partir da experiência de usuários de um Centro de Atenção Psicossocial (CAPS). Guiada pelas pistas do método cartográfico, e através da construção de mapas afetivos e da realização de trajetos pela cidade, foi possivel acompanhar como os participantes tecem multiplicidades de territórios e redes vivas ao longo de seus itinerários, escapando de lugares instituídos pela lógica manicomial e concretizando princípios da desinstitucionalização na micropolítica de seu cotidiano. Neste movimento, informam-nos reflexões sobre quais cidades desejamos construir, reinventando coletivamente os territórios urbanos como mais sensiveis e permeáveis às forças instituintes, com novas formas de convivência e produção da diferença. Simultaneamente, trazem reflexões sobre de que formas estas vivências singulares de cidade podem comparecer e potencializar os itinerários terapêuticos de uma clínica que se propõe funcionar a partir da lógica do território.

Palavras-chave Saúde mental, Desinstitucionalização, Serviços de saúde mental, Cidades, Saúde pública 


\section{Introdução}

A experiência da loucura, como outros desvios do que se construiu como normalidade, foi historicamente relacionada a um grande isolamento - tanto espacial, quanto social e simbólico ${ }^{1}$. Com a produção da loucura como "doença mental", âmbito de especialidade da psiquiatria, tornada hegemônica no século XIX, o diagnóstico médico-psiquiátrico passou a poder determinar a negação do direito à liberdade de um sujeito. No contexto das perversas práticas modernas de "tratamento" da loucura, os sujeitos ditos loucos pelo saber psiquiátrico foram asilados em instituições manicomiais, desérticos e desertificantes territórios, e submetidos a inúmeras violações dos direitos humanos ${ }^{2}$.

A garantia legal do direito ao cuidado em liberdade é conquista recente e coletiva do movimento da luta antimanicomial. A Reforma Psiquiátrica Brasileira (RPB) concretiza conquistas como a criação dos Centros de Atenção Psicossocial (CAPS) como serviços substitutivos em saúde mental, na década de 1980 , e a Lei no 10.216/2001, que "dispõe sobre a proteção e os direitos das pessoas portadoras de transtornos mentais e redireciona o modelo assistencial em saúde mental"3. A partir destas conquistas, novas questões se colocam para os processos de desinstitucionalização da loucura. Cabe aos CAPS, dentre outros agentes, o desafio de sustentar no cotidiano do trabalho estes direitos, constituindo-se "em serviço ambulatorial de atenção diária que funcione segundo a lógica do território"4.

Para tal, desinstitucionalizar se mostra um desafio mais amplo que a desospitalização e a negação ao manicômio enquanto instituição total e espaço físico. $\mathrm{Na}$ instituição da loucura prevalecem a lógica e cultura manicomiais como um "arsenal de saberes, verdades, normas e lugares instituídos sobre e para a loucura e o louco"s, que atravessam o tecido social como um todo. $\mathrm{Na}$ dimensão simbólica do território, complexificase a efetivação da RPB, pois, fora dos muros dos manicômios, a cidade continua erigindo muros simbólicos em suas formas de se relacionar com a loucura ${ }^{1}$.

Esta pesquisa, debruçada no eixo território -loucura-desinstitucionalização, desenrola-se na cidade de São Paulo, maior da América Latina e exemplo grandioso dos centros urbanos como megamáquinas de produção de subjetividades, prenhes de contradições. Nelas, "o território tanto quanto o lugar são esquizofrênicos, porque de um lado acolhem os vetores da globalização, que neles se instalam para impor sua nova ordem, e, de outro lado, neles se produz uma contraordem, porque há uma produção acelerada de pobres, excluídos, marginalizados"' (p. 114).

Nesta tensão constituinte, segundo Félix Guattari ${ }^{7}$, desenrola-se o embate entre uma forma-Estado, representante dos vetores de totalização, homogeneização e estratificação da diferença, e forma-cidade, em que se dão os vetores de dispersões e fluxos de singularidades. Na formacidade persiste uma potência de heterogênese, a partir da qual o conceito de cidade subjetiva nos instrumentaliza a pensar a cidade como território plural, no qual coexistem múltiplas cidades singulares, a partir dos pontos de vista de cada um de seus habitantes.

Estas inúmeras cidades subjetivas são formadas de fluxos singulares de conexão, nos quais cada sujeito tece seus territórios existenciais enquanto "espaços construídos com elementos materiais e afetivos do meio, que, apropriados e agenciados de forma expressiva, findam por constituir lugares para viver"9 (p. 599). Nestes, desenrola-se a possibilidade de habitar a cidade como território de trocas sociais e afetivas, tecendo redes vivas que sejam capazes de sustentar a existência.

Através de agenciamentos de componentes heterogêneos, cada sujeito traça contornos e sentidos como centros de significância territorializantes 9 , construindo em seus territórios existenciais moradas singulares, como ninhos que sustentam e acolhem a vida, protegendo-a do caos. Estes ninhos abrigam a possibilidade de novos voos que virão a reconfigurar suas redes, singulares e rizomáticas, que se fazem processuais e mutáveis a partir de um "desejo de asas" ${ }^{10}$ (p. 122), constituindo-se cada sujeito como nômade e protagonista de seu tecer.

O direito ao cuidado em liberdade, para os sujeitos considerados loucos, inaugura a possibilidade do direito à cidade como direito a esta construção. Se a cidade segue impondo, porém, desamparo, estigma e desigualdades de diversas ordens frente à experiência da loucura, estes se interpõem à concretização deste direito. Essas violências trazem a ameaça de novas cronicidades, reatualizados adoecimentos nos quais uma experiência de desterritorialização desemboca numa reterritorialização em territórios muito enrijecidos ou muito fechados, ou a própria desterritorialização se faz morada prolongada de um sujeito ${ }^{10}$.

Segundo Pande e Amarante ${ }^{11}$, corre-se o risco de construir relações de dependência entre as re- 
des de saúde e os usuários da saúde mental, onde se reatualize a lógica manicomial em circuitos sanitários rígidos e fechados, centrados nos saberes dos profissionais da saúde, que sigam endurecendo as possibilidades de trocas e circulação mais amplas. Ao fecharmos tais circuitos, nossas instituições de saúde se tornam também cronificadas. De maneira comparável, ao se endurecerem em fluxos de homogeneização, fechando-se para o encontro entre alteridades, a cronificação adoece também nossas cidades.

Frente ao desafio da desinstitucionalização, que se coloca, portanto, simultaneamente para as existências dos sujeitos, para as redes de saúde e para as cidades, esta pesquisa se propõe conhecer algo do território como "espaço relacional no qual a vida pulsa"9 (p. 598), a partir da perspectiva de usuários da saúde mental que o habitam. Interessa permitir que seus itinerários de cidade compareçam nos itinerários terapêuticos de uma clínica que se propõe funcionar a partir da lógica do território, e experimentar de que maneiras movimentam o debate sobre o direito às cidades que queremos construir.

\section{Metodologia}

A colheita de dados ${ }^{12}$ - compreendida como ato de produção de mundos, contraposta à "coleta" de dados, que se pretende ato de extração a partir de mundo prévio e estático - foi realizada entre outubro e dezembro de 2018, em um CAPS da região central da cidade de São Paulo. Aprovada pelo Comitê de Ética em Pesquisa com Seres Humanos do Instituto de Psicologia da USP (CEP-IPUSP), esta pesquisa acessou seus interlocutores a partir do cotidiano de trabalho, tendo sido realizada na instituição onde a pesquisadora ocupava também papel de trabalhadora, psicóloga, e pós-graduanda do Programa de Aprimoramento Profissional (Secretaria do Estado da Saúde de São Paulo).

A construção de ferramentas metodológicas foi guiada por pistas do método cartográfico, como possibilidade para o pesquisar como acompanhamento de processos e mergulho no plano da experiência e nos territórios existenciais ${ }^{13,14}$. Este ofereceu pistas, também, de princípios ético-estético-políticos transversais às ferramentas metodológicas, como a importância de se lançar com dedicação atenta, disponibilidade e abertura afetiva à experiência ${ }^{15}$. Foram registrados e experimentados com usuários do CAPS seus itinerários de cidade e territórios existenciais que ali se tecem, buscando escutar como suas experiências singulares contribuem para os processos de desinstitucionalização da loucura, e para a construção das cidades que queremos.

Foram convidados três participantes, segundo os seguintes critérios: frequentar o CAPS três vezes por semana ou mais; ser portador do Bilhete Único Especial SPTrans, que confere gratuidade no transporte municipal, evitando custos advindos da participação; o vínculo - definido pela Política Nacional de Atenção Básica como a "construção de relações de afetividade e confiança entre o usuário e o trabalhador da saúde [... $]^{\prime 16}$ (p. 21) - entre participante e pesquisadora enquanto trabalhadora do serviço; e consentir voluntariamente participar, de acordo com Termo de Consentimento Livre e Esclarecido.

Foram realizadas entrevistas individuais semi-dirigidas ${ }^{17}$, registradas através de mapas afetivos da cidade $^{18}$ que cada participante produziu em folha formato A2 ao longo do encontro. As perguntas disparadoras exploram quais seus lugares de frequentação cotidiana, lugares de referências da cidade, e lugares de memórias, relações e afetos, que se acessam e atualizam na experiência da entrevista. Também investigam, e instigam a registrar no mapa, os itinerários, trajetos e errâncias entre os locais mencionados.

Ao final da entrevista foi proposto a cada participante a realização de um trajeto acompanhado pela pesquisadora, escolhido por cada um a partir do critério da importância em seu cotidiano, e combinado em ocasião de sua preferência. Como dados adicionais, construiu-se imagens dos itinerários por sobre mapa geográfico da cidade, por meio da ferramenta My Maps do Google Maps, com localização aproximada para os endereços pessoais, a fim de proteger a privacidade dos participantes. Foram também produzidos, pela pesquisadora, diários de campo a partir dos encontros.

Para a apresentação dos resultados, os nomes de todos os participantes foram trocados por nomes fictícios escolhidos por si próprios, a fim de ocultar suas identidades reais. Foram também ocultados, nos mapas produzidos, logradouros e nomes pessoais que pudessem expor identidades.

\section{Resultados}

\section{Marcos}

Marcos, 59 anos, é alto, branco e simpático, constantemente cumprimentando outros fre- 
quentadores do CAPS pelos corredores. É usuário do serviço desde que se mudou para São Paulo, há dez anos, a partir de encaminhamento do CAPS de sua cidade natal. Frequenta-o quase todos os dias, podendo ser encontrado geralmente no jardim, próximo à mesa onde é servido café e chá duas vezes ao dia; também frequenta as assembleias do serviço e as visitas a museus, organizadas pela oficina de artes. $\mathrm{O}$ trajeto de sua casa ao CAPS é o primeiro registro de seu mapa (Figura 1). A partir deste, o desenho vai se ampliando em todas as direções, em numerosos lugares e trajetos, de forma que Marcos se preocupa que "podem não caber no papel" (fala de M.).

Originário de T., cidade do interior do Estado de São Paulo com menos de 50 mil habitantes, desde a mudança para a capital divide com o irmão um apartamento na região central, cujo custo ajuda a cobrir com sua renda mensal de um salário-mínimo, proveniente de uma aposentadoria por invalidez. Diz gostar muito de São Paulo, que descreve como "uma grande megalópole, onde tem tudo"; mas é aquela na qual nasceu que denomina como "minha cidade" (falas de M.). Visita-a uma vez ao ano, hospedando-se com familiares, viagem cujo trajeto registra em seu mapa: a saída de uma São Paulo representada por prédios; o ônibus na estrada; e a chegada a T., retratada por grandes árvores, a igreja da praça matriz, e ele mesmo, andando de braços esticados em sua direção.

A maior parte dos registros se concentra na região central, próximos à sua moradia. O Parque Ibirapuera, mais afastado deste circuito, comparece como espaço que não frequenta, mas que abarca memórias importantes de um piquenique realizado com usuários e trabalhadores do CAPS. Conta, também, que caminha bastante sozinho pelas ruas quando alegre - já quando está mal, relata que a providência é buscar o CAPS. As caminhadas de Marcos exercem papel central na estruturação de seu cotidiano, tendo caráter planejado e rotineiro. A cada dia, escolhe um dentre os trajetos predefinidos por si para caminhar, cujas ruas e distâncias descreve com exatidão, sem hesitar.

Sua descrição do trajeto para o Chóping (SIC) é exemplo: sai a pé do CAPS todas as terças e quintas-feiras, após a garrafa de café ser servida para os usuários às $10 \mathrm{~h}$ da manhã. Após passar protetor solar e ir ao banheiro, caminha até o local, seguindo pela avenida. Entra e olha vitrines até o horário de retornar para o almoço, que é servido no refeitório do CAPS ao meio-dia. Organiza-se ao redor destas rotinas institucionais que, com seus horários e atividades coletivos, produzem o tempo como fator que localiza e qualifica o pertencimento nos espaços que frequenta, compondo contornos e territórios.

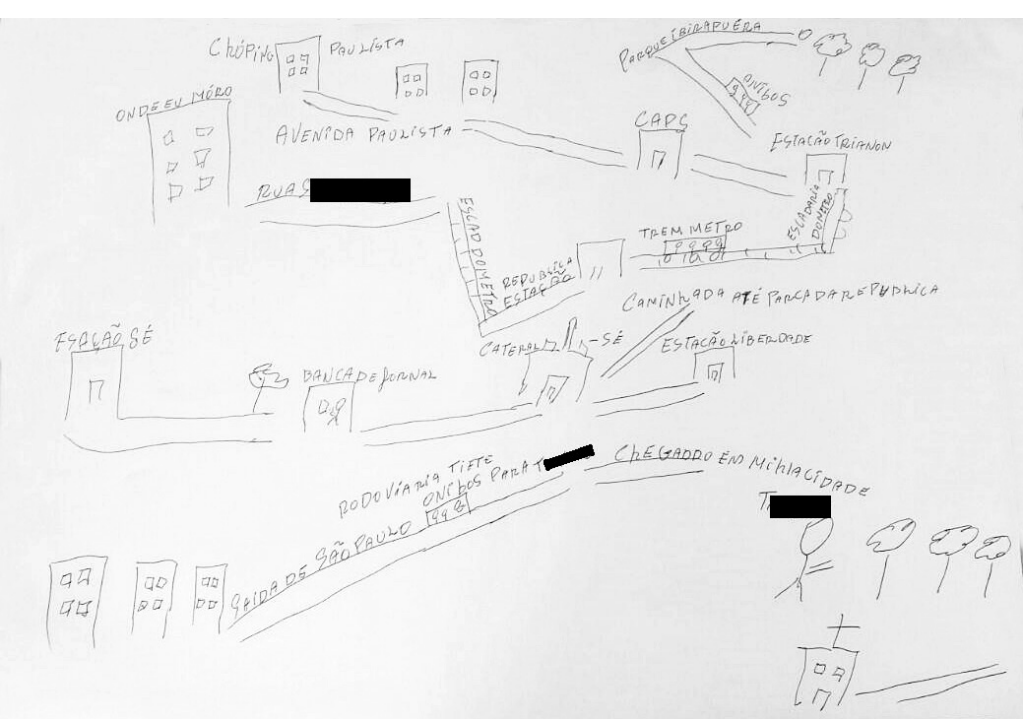

Figura 1. Mapa afetivo da cidade de Marcos. 
É este trajeto que escolhe realizar com a pesquisadora na segunda etapa da pesquisa. Apesar de realizá-lo há anos, e contar que o aprecia especialmente para admirar as lojas, é nesta visita acompanhada que realiza a que relata ser sua primeira compra neste espaço: um par de chinelos. Sua relação com os territórios do consumo emerge com centralidade ao longo da experiência, expondo contradições na maneira como lhe é possível acessar os circuitos de trocas financeiras, conforme se vislumbra em trechos do diário de campo:

Me chama a uma loja de joias e relógios Rolex, chamando-me atenção ao número de dígitos dos preços. [...] Comento sobre o perigo de assalto ao portar itens tão caros, ao que Marcos comenta 'essas pessoas só andam de carro, não andam na rua que nem a gente. Pergunto o que ele faria se fosse muito rico: acha que teria um Rolex, contrataria um psiquiatra particular e deixaria de ir ao CAPS. Surpresa com esta resposta, comento que vários psiquiatras do CAPS também atendem em consultório particular, e questiono o porquê escolheria pagar pelo serviço que acessa gratuitamente pelo SUS. Rindo, me responde que os psiquiatras do CAPS são bons, e que gostaria de contratar como particular seu próprio médico atual [...].

\section{Grilo}

Grilo é um homem alto e magro, de 47 anos. Preocupa-se em vestir roupas sociais, pois diz que estar "bem-vestido" é um marcador importante para "passar boa impressão" (falas de G.), disputando com os pré-julgamentos negativos que conta receber por ser negro, pobre e não ter moradia fixa. Grilo está há quatro anos em situação de rua, desde que conflitos familiares o levaram a sair do local que registra no mapa como "Minha Casa Saudades" (Figura 2). Pernoita em Centros Temporários de Acolhimento (CTAs) da região central de São Paulo, por meio de vagas que solicita diariamente.

Grilo é trabalhador do Bazar do Ponto Benedito de Economia Solidária e Cultura, que fomenta a inclusão social através do trabalho e da cultura. A partir de escala decidida semanalmente pela autogestão dos trabalhadores, trabalha em média três dias por semana, cumprindo suas responsabilidades trabalhistas com assiduidade e organização, e tirando desta ocupação sua única renda, que soma em torno de 120 a 200 reais mensais. É também, há dois anos, integrante do chamado Trecho 2.8, representado em seu mapa - um projeto de criação e pesquisa em comuni- cação voltado a pessoas em alta vulnerabilidade social, ligado ao Ponto Benedito e localizado no mesmo bairro $^{19}$.

Frequenta o CAPS na maioria dos períodos em que não está nestes projetos, tendo relações amigáveis com diversos usuários e técnicos do serviço. É integrante do time de futebol, e canta sempre músicas de rock e punk nos saraus, estilos dos quais é fã - motivo que o leva às cidades do interior de São Paulo, que registra em seu mapa, para frequentar "bons barzinhos de rock" com amigos. O CAPS é o último local que lembra de registrar, contando ter no serviço referência de onde ir quando se sente triste.

Outras providências frente à tristeza são: caminhar sozinho pelas ruas, ir ao Bazar, ou ao estádio de futebol na Barra Funda, onde encontra amigos para assistir às partidas por fora do estádio, sem comprar ingressos. Queixa-se da falta de dinheiro, e cita outros locais gratuitos de lazer que frequenta: "barzinhos na Mooca, de domingo o forró no MASP, a Paulista fechada pra carros e aberta pra gente" (fala de G.). Um trajeto mais cotidiano, porém, é o da rotina de trabalho, pelo qual inicia a construção de seu mapa, traçando o caminho de transporte público do CTA ao Bazar/ Trecho 2.8. É o trajeto do CAPS a estes espaços que Grilo escolhe realizar com a pesquisadora, na segunda etapa da pesquisa.

A visita mostrou como estes são, para G., espaços importantes de afetividade, nomeando todos os presentes no local como seus amigos. Esta se iniciou pelo Bazar, onde apresenta a pesquisadora ao espaço e aos demais trabalhadores, contando sobre sua experiência no local. Em seguida, guia a caminhada para a sede do Trecho 2.8. No dia da visita, realizava-se a reunião da equipe do projeto, formada na ocasião por seis pessoas, tendo como pauta trabalhar na escrita de roteiro para uma radionovela.

A trama da novela que constroem tem como personagem principal um cachorro, que foge de sua dona "porque ela quer mandar nele toda hora" (fala de G.). Na fuga, que o coloca inicialmente no desamparo do desgarramento, desvia de perigos, tais como ser atropelado por carros ou ser capturado pela carrocinha. Ajudado por um amigo pássaro, chegam a uma praça onde encontram o "Velhinho Bonzinho", personagem cujas falas foram escritas e interpretadas por Grilo. Este personagem, em situação de rua como muitos dos integrantes do projeto, se compadece ao assistir a fuga do cachorro. Convida-o a morar com ele na praça e, assim, serem companhia um para o outro; proposta que o cachorro aceita, feliz. 


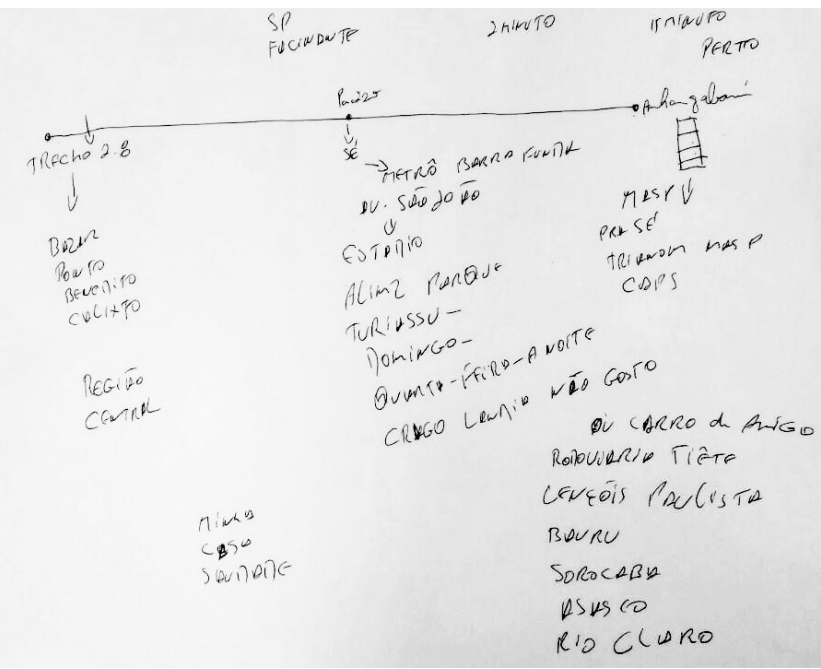

Lê-se, no topo: "SP FACINANTE - 2 MINUTO

- 15 MINUTO PERTO”.

Sobre a linha: "Paraiso - Anhangabaú".

Sob a linha, à esquerda: TRECHO 2.8 -> BAZAR/PONTO/BENEDITO/CALIXTO/ REGIÃO/CENTRAL."

Sob a linha, ao centro: -> SÉ -> METRÔ

BARRA FUNDA/AV. SÃO JOÃO -> ESTADIO/

ALIANZ PARQUE/TURIASSU - / DOMINGO

- / QUARTA-FEIRA-A NOITE / CRAGO

LANDIA NÃO GOSTO”.

Sob a linha, à direita: "MASP -> PRA SÉ/

TRIANON MASP/CAPS”.

Abaixo, à esquerda: "MINHA CASA

SAUDADE".

Abaixo, à direita: "DU CARRO DE AMIGO/

RODOVIARIA TIÊTE/LENÇÓIS PAULISTA/

BAURU/SOROCABA/OSASCO/RIO CLARO".

Figura 2. Mapa afetivo da cidade de Grilo.

Fonte: Mapa afetivo da cidade de São Paulo, elaborado por Grilo durante a entrevista.

No encerramento da entrevista, Grilo comenta que "São Paulo é uma cidade fascinante", escrevendo "SP Facinante" na parte superior da folha, como um título. A fascinação desta, que descreve como "uma cidade bonita, de gente bonita, frio e garoa”, também é feita de suas contradições, como as expressas no roteiro da radionovela construída pelo grupo, que complexifica o conceito de liberdade. A partir do desamparo vivido, da falta de emprego e moradia fixos e de uma rede familiar de apoio, Grilo, tal como o personagem da novela, também passa a transitar intensamente entre as ofertas e desigualdades da região central da cidade e os encontros que essa lhe proporciona. Nestas andanças constrói para si, ao longo dos anos, uma rede de territórios e relações em um Centro no qual conta se sentir muito bem recebido, e onde transita com a segurança, fluidez e autonomia de quem pertence.

\section{Carolina}

Carolina, 46 anos, negra, é natural de Senhor do Bonfim, na Bahia. Mudou-se para São Paulo aos 18 anos, com a família - não voltou a visitar seu Estado natal e diz não ter vontade. É mãe de filhos nascidos em São Paulo, dos quais não tem a guarda, nem permissão para visitar, "porque não dei conta de cuidar" (fala de C.). Alguns de seus filhos estão em Serviço de Acolhimento Institucional, e outros foram adotados. Sem fontes de renda, a busca de ofertas socioassistenciais motiva largamente sua circulação na cidade, como nas idas ao Refeitório e Núcleo de Convivência Penaforte Mendes, registrado em seu mapa (Figura 3), local onde recebe refeições gratuitas e doação de roupas.

Em "favela, pensão e albergue" (fala de C.), enfrentou diversas formas de habitação precarizadas e irregulares, sujeitas a uma permanente transitoriedade. Atualmente, vive em um prédio com 60 famílias, na ocupação de um movimento de luta por moradia da região central da cidade. Aliou-se ao movimento em busca de uma habitação, por indicação de um colega da cooperativa de reciclagem na qual trabalhava, anos atrás. Esta vivência, com reuniões obrigatórias diárias para organização do movimento, que conta por vezes serem um fardo, aparece também em suas falas como possibilidade de experiência comunitária e mobilização política ativa frente à desigualdade.

Casada há 20 anos, conta que seu marido a acompanha na quase totalidade de seus itinerários, justificando se desagradar com olhares masculinos que Carolina possa receber na rua. Transita sozinha somente na ida matinal ao CAPS 


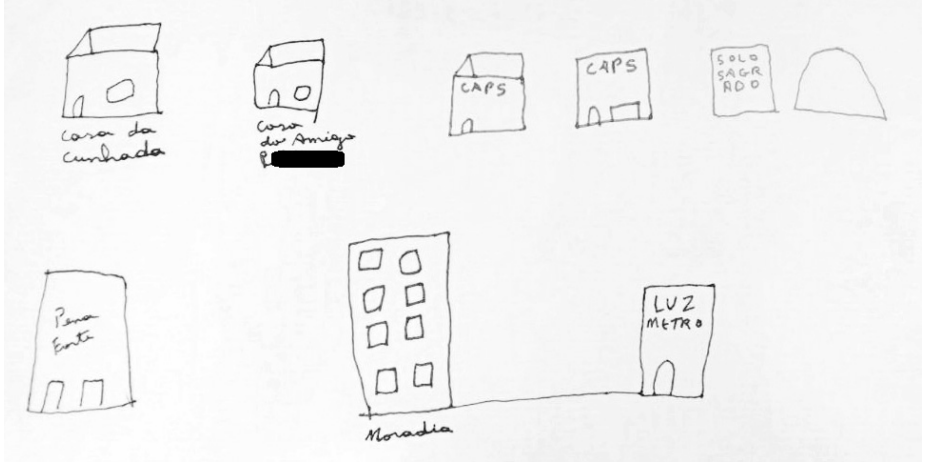

Figura 3. Mapa afetivo da cidade de Carolina.

Fonte: Mapa afetivo da cidade de São Paulo, elaborado por Carolina durante a entrevista.

e no tempo despendido dentro do serviço - na volta, o marido a busca -, e para comprar cigarros para ele. Menciona espaços que gostava e há cinco anos deixou de frequentar devido a essas determinações, como o Parque da Juventude e a casa de P., uma amiga. Não a tendo encontrado desde então, mantém contato com P. via telefone celular, tornado ferramenta de circulação afetiva em territórios para além do restrito território doméstico.

O Solo Sagrado, parque de cunho religioso na Zona Sul da cidade, é outro local do mapa que escapa deste circuito, descrito como território da memória de preciosas trocas sociais e afetivas. Visitou o parque somente uma vez, 10 anos atrás, com um grupo de mulheres do qual fazia parte, onde "podia compartilhar a vida e os problemas" (fala de C.). O CAPS também comparece como território de tais possibilidades de trocas, motivo pelo qual escolhe pintá-lo de "verde-esperança", conforme trecho de diário de campo:

Respondendo sobre em quais lugares da cidade se sente melhor, mais bem-vinda, Carolina diz: 'Aqui na Bela Vista, no CAPS'. Conta que desenhou $o$ CAPS em verde, que significa esperança [...] Diz que o que gosta no CAPS, o qual frequenta há 7 anos, é que 'aqui as pessoas conversam comigo'. Conta que, em casa, ela e o marido não conversam, somente ficam em silêncio e assistem à televisão. Diz que eles não têm dinheiro para sair, e que também não saem para passeios gratuitos [...].

Carolina afirma repetidamente que "São Paulo é uma mãe", sob um ideal de figura materna que a todos acolhe e cuida: "É maravilhosa, tem tudo. Aqui eu ganho roupa no Penaforte; na Bahia estaria com roupa furada. Tem trabalho, a vida é melhor [...] É a melhor cidade" (fala de C.). Seu discurso expressa gratidão pelas possibilidades de sobrevivência que encontra, ao mesmo tempo em que relata sua situação de vulnerabilidade, com acesso restrito às ofertas citadas. Revela, assim, que a cidade que descreve maternal escapa deste hegemônico e insuficiente ideal de maternidade - tal como na própria história de Carolina, que vive contradições em uma experiência de maternidade atravessada por grandes cargas de culpas e saudades.

Carolina chegou a escolher o trajeto que realizaria com a pesquisadora na segunda etapa da pesquisa: do CAPS para sua casa. Demonstrou animação com a possibilidade da visita em seu lar, embora "não tenha fogão para passar um café" (fala de C.). Foi necessário, porém, suspender a visita, devido à preocupação expressa recorrentemente por C. após combiná-la: estava receosa de incomodar o marido, que necessariamente acompanharia o trajeto. Julgou-se que tal intervenção poderia causar efeitos disruptivos, para suas relações e organização de vida, que ultrapassariam o escopo ético de realização da pesquisa.

\section{Discussão}

Da amostra de três pessoas, dois homens e uma mulher, todos têm acima de 40 anos de idade, sem inserção no mercado formal de trabalho, e 
possuem renda mensal de até um salário-mínimo. Dois de três enfrentam vulnerabilidades graves em relação à moradia. Falta de rede de apoio familiar e o tratamento em saúde mental de longo prazo completam quadros de alta vulnerabilidade psicossocial, conforme o perfil atendido pelos CAPS. Percebe-se efeitos do racismo ${ }^{20}$ : os dois participantes em mais graves situações de vulnerabilidade são pessoas negras. A participante mulher tem seus itinerários diretamente restritos por seu cônjuge. As questões de gênero, raça e desigualdade social são temas presentes nessas existências e relembram a impossibilidade histórica de pensar a loucura sem estes determinantes.

Todos os participantes se engajaram na produção da pesquisa com interesse e dedicação. Passaram, a partir dos convites, a buscar sempre informações sobre o andamento da pesquisa e sobre a qualidade e utilidade de suas produções, apropriando-se do papel de copesquisadores. Nestes efeitos, que apontam para a inseparabilidade entre conhecer e fazer reafirmada no método cartográfico ${ }^{12}$, observamos como o próprio ato de pesquisar junto pode movimentar existências, a partir do reconhecimento da importância das narrativas de cada sujeito sobre si, sua vida e sobre a cidade que habita.

Na realização dos trajetos na rua e dos combinados para a pesquisa, todos os participantes se imbuíram, em relação à pesquisadora, de responsabilidade de anfitrião em seus territórios. Nesta experiência, a generosidade destes sujeitos relembra a importância de, enquanto profissionais da saúde, nos deixarmos ser guiados, percorrendo os ritmos e caminhos daqueles que acompanhamos e desenhando junto os traços que se projetam do percurso. A construção de mapas afetivos singulares também se mostrou potente ferramenta, resgatando a multiplicidade indócil do território onde coabitam inúmeras cidades subjetivas, em contraste com os mapas geográficos que homogeneizam e controlam os fluxos urbanos.

A Figura 4 ilustra os itinerários das redes dos participantes, conforme seus relatos e sobrepostas ao mapa geográfico da cidade. Os resultados mostram as ruas como cenário e matéria de agenciamentos nesta produção, persistindo nelas as possibilidades de dispersões e fluxos de singularidades e de constituição de novos planos de subjetivação, como espaços de encontro e composição entre alteridades, onde as cidades se fazem platôs - zonas de intensidade contínua nos quais se tecem territórios ${ }^{21}$.

Os espaços públicos comparecem com centralidade nos mapas construídos, mostrando-se ofertas centrais especialmente para aqueles que enfrentam dificuldades socioeconômicas. Fortalecer a habitabilidade destes espaços, constituindo-os como verdadeiros territórios coletivos de sociabilidade, circulação, convivência e produção da diferença, rejuvenesce a cidade e possibilita a constituição de ricas moradas, compartilhadas e singulares, para os sujeitos que ali habitam, alargando as redes de espaços e relações nas quais é possível viver.

Os resultados apontam também como persistem na cidade de São Paulo, simultaneamente a estas multiplicidades, vetores da violência, da marginalização e da estratificação da diferença. Habitando as contradições de nossas grandes cidades, que, como no relato dos participantes, oferecem tudo, mas não para todos, fortalecer a desinstitucionalização é também investir na construção coletiva de reinvenções do território urbano, tornando-o mais sensível e permeável às forças instituintes, produzindo descontinuidades em suas formas enrijecidas:

Como romper tal silenciamento? Como borrar as paisagens esquadrinhadas por linhas horizontais e verticais, entre avenidas e prédios, para traçar outros planos de subjetivação? O que fazer para transversalizar os espaços estriados das duras arquiteturas montadas para grandes e silenciosas maiorias? No questionamento das formas enrijecidas que vão tomando conta de nossos espaços urbanos, encontro uma proposição transgressora na filosofia da diferença a subsidiar nossas reflexões: Mesmo a cidade mais estriada secreta espaços lisos: habitar a cidade como nômade, ou troglodita. [...] é neles que a luta muda, se desloca, e que a vida reconstitui seus desafios, afronta novos obstáculos, inventa novos andamentos, modifica os adversários. $^{8}$ (p. 214)

A lógica capitalística globalizada, privilegiando o crescimento econômico como sinônimo de desenvolvimento, compartimentaliza a cidade em espaços de produção e reprodução da força de trabalho, e as ruas como mero local de passagem. Acompanhar o tempo humano das cidades subjetivas e seus itinerários, porém, convida a desacelerar esta lógica e imaginar territórios guiados pelo ritmo de nossas histórias individuais e coletivas. $\mathrm{O}$ conceito de direito à cidade deixa de ser compreendido como mero acesso a equipamentos e serviços disponibilizados pelo poder público, e passa a se sustentar do protagonismo de seus habitantes: o direito à cidade como infraestrutura aberta, a ser disputada e transformada a partir do que defendamos coletivamente para ela. 


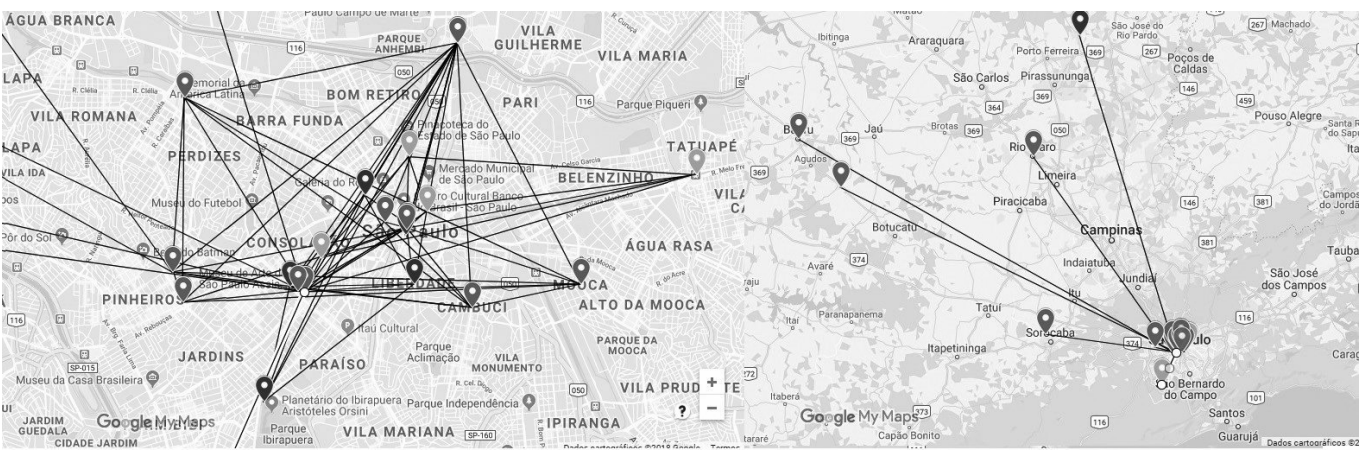

Os pontos representam os locais levantados nos mapas de cada participante, com linhas traçadas entre eles. As redes traçadas para cada um dos três participantes estão sobrepostas. À esquerda, encontram-se representadas por sobre mapa geográfico da região central da cidade de São Paulo; à direita, representadas por sobre mapa geográfico do Estado de São Paulo.

Figura 4. Redes de itinerários de Marcos, Grilo e Carolina, sobre mapa geográfico.

Fonte: Google Maps.

Nesta construção, o próprio processo de desinstitucionalização se mostra experiência desterritorializante para a cidade, a partir do convívio inevitável com subjetividades desviantes, antes confinadas nos manicômios e hoje habitando novos territórios e papéis sociais a cada dia. A loucura, enquanto potência criativa, disruptiva e experiência de alteridade radical, confronta a cidade com a necessidade de interrogar suas próprias prescrições aprisionantes. Enlouquecer um pouco mais as cidades, apostando em sua potência de heterogênese, e reinventando-nos em novas formas de conviver com a diferença, é um ganho civilizatório que beneficiaria a todos:

[... a loucura, vista em sua peculiar dimensão de 'avesso da razão', pode trazer aos espaços públicos algo que sistemática, ideológica e progressivamente veio deles sendo extirpado: as vozes da diferença. Não é simplesmente uma questão terapêutica para aqueles que padecem de sofrimento mental (ainda que também o seja!). O direito à loucura circular na cidade é também o direito às cidades conviverem com muitas forças que compõem as subjetividades, e o dever de todo estado democrático de criar espaços possiveis para que essas diferenças circulem livremente $^{8}$. (p. 50)

A escuta deste nível micropolítico dos territórios existenciais traz "os lugares onde as existências furam os muros institucionais [...] lugar dos processos de encontros e suas atualizações das relações de poder" ${ }^{22}$ (p. 148). Na relação com a cidade, a desinstitucionalização vai se concretizando na riqueza destas redes vivas de conexões existenciais em que se dão as trocas sociais e afetivas. Estas, tecidas nos cotidianos destes sujeitos para além dos muros dos serviços de saúde, desafiam e transgridem continuamente também as concepções asilares dos processos de institucionalização e cronificação, que lhes capturam sob a insígnia da doença, da exclusão e marginalização.

Para nossas instituições de saúde, que acontecem na dobra entre, de um lado, "a rede institucional, $[. .$.$] dando referência, norma e disciplina$ sobre a vida do usuário; de outro, a rede singular, rizomática, construída no seu protagonismo [...]"23 (p. 873), esta escuta permite pensar, como analisadores da clínica ético-política de um serviço como o CAPS, a existência ou não de troca, pertencimento, e fortalecimento da autonomia, contraposto ao manicômio como lugar de troca zero ${ }^{24}$. No discurso dos participantes, o CAPS comparece como importante local de produção de saúde e de vida. Mencionam-no, no contexto da cidade, como uma morada dentre várias, da qual cada um usufrui de maneiras distintas. Vemos, desta perspectiva, uma instituição que se faz ninho e se faz muitas, acolhendo os sujeitos em suas contradições, sem confrontá-las como encruzilhadas e possibilitando vivê-las no encontro com outros.

A tensão entre as redes institucionais e as multiplicidades que seus usuários constroem e vivem em seus territórios convoca a tornar as instituições de saúde cada vez mais permeáveis à "vida que está lá fora" ${ }^{25}$, acompanhando e apoiando o alçar de novos voos. Nas suas múlti- 
plas existências fora dos "muros do serviço", estes sujeitos carregam "um conjunto vivo de estratégias, de novas modalidades, formas de criar sentido, de produção de outras redes, de outros territórios existenciais" ${ }^{22}$ (p. 23), que muitas vezes permanecem desconhecidos ou subaproveitados pelos projetos institucionais.

\section{Considerações finais}

As ferramentas metodológicas propostas possibilitaram o objetivo de mergulhar com os participantes em parte do processo de produção de múltiplas existências em seus itinerários de cidade. Os resultados apontam para a riqueza de estar junto em territórios onde não lhes é reservado o papel de louco, delirante, embotado, cronificado, como por vezes são descritos no olhar da equipe de saúde implicada em seu cuidado; onde, tampouco, são restritos a ocupar posições inferiorizadas ou de periculosidade, pelo estigma da loucura, do racismo ou da pobreza. Circulam, nestes territórios, por muitos outros papéis.

Se a concretização e sustentação do direito ao cuidado em liberdade e do direito à cidade, frente à história de asilamento e isolamento da loucura, seguem como processos de disputa, as experiências vivas dos participantes nos lembram que o instituído é apenas pedaço da realidade - campo amplo de possibilidades, que emergem e se instituem em uma história de embates na qual estamos também inseridos. Na micropolítica do cotidiano, estes sujeitos vão concretizando os princípios da desinstitucionalização no tecer de multiplicidades de territórios e redes ao longo de seus itinerários.

Frente às contradições de nossas instituições de saúde, que se desenrolam entre os endurecimentos institucionais e a possibilidade de se constituírem como territórios coletivos da cidade, atuando na garantia destes direitos, interessa apostar na aliança com os usuários dos serviços enquanto protagonistas de suas existências e projetos de cuidado. Sugere-se a necessidade de novas pesquisas, experiências e práticas onde se promova a circulação das instituições de saúde junto com seus usuários pela cidade, alargando os itinerários terapêuticos de uma clínica que se propõe operar a partir da lógica do território.

Aponta-se a necessidade de as experiências destes sujeitos informarem também a transformação de nossas cidades e o desenvolvimento de novas políticas públicas e urbanas que assegurem, cada vez mais, a construção de cidades verdadeiramente democráticas, com novas formas de convivência e produção da diferença. Nos embates e tensões criadoras que surgem destas contradições e formam parte do complexo campo onde a vida acontece, a sabedoria cotidiana das multipliCidades - múltiplas cidades e multiplicidades de modos de existir, transitar e estar - de sujeitos ditos loucos mostram-se antídotos possíveis para as croniCidades - cronificações e enrijecimentos das cidades e dos modos de existir - que adoecem existências individuais, coletivas e institucionais.

Assim, superar o isolamento historicamente imposto à experiência da loucura, fortalecendo a desinstitucionalização e os princípios da Reforma Psiquiátrica Brasileira, desafia a contagiar sujeitos, instituições e cidades com um desejo de asas, implicando-se na construção de territórios, tecidos com a matéria-prima dos encontros e das relações, onde a vida se torne mais vivível para todos. Para tal, faz-se necessário se deixar guiar e impregnar pela potência destas multipliCidades que pedem passagem, contagiando e polinizan$\mathrm{do}^{26}$ - com uma lufada de vento, ou, ao menos, com alguma vontade de respirar. 


\section{Referências}

1. Saffiotti A. Atenção em saúde mental a partir da noção de território: uma reflexão sobre os Centros de Atenção Psicossocial [tese]. São Paulo: Universidade de São Paulo; 2017.

2. Castel R. A ordem psiquiátrica: a idade de ouro do alienismo. Rio de Janeiro: Graal; 1978.

3. Brasil. Lei no 10.216 de 6 de abril de 2001. Dispõe sobre a proteção e os direitos das pessoas portadoras de transtornos mentais e redireciona o modelo assistencial em saúde mental. Diário Oficial da União. Brasília, DF; 2001.

4. Brasil. Portaria no 336 de 19 de fevereiro de 2002. Estabelece CAPS I, CAPS II, CAPS III, CAPSi II e CAPS ad II. Diário Oficial da União. 2002 fev.

5. Paulon SM, Trepte R, Neves R. Todo dia se faz tudo sempre igual...? Recortes da desinstitucionalização da loucura Brasil-Itália. Mnemosine 2013; 9(2):180-198.

6. Santos M. Por uma outra globalização (do pensamento único à consciência universal). Rio de Janeiro: Record; 2001.

7. Guattari F. A restauração da cidade subjetiva. In: $\mathrm{Ca}$ osmose: um novo paradigma estético. Rio de Janeiro: Editora 34; 1992. p. 169-178.

8. Paulon SM. Quando a cidade "escuta vozes": o que a democracia tem a aprender com a loucura. Interface 2017; 21(63):775-786.

9. Lima EMFA, Yasui S. Territórios e sentidos: espaço, cultura, subjetividade e cuidado na atenção psicossocial. Saude Debate [periódico na internet]. 2014 [acessado 2020 out 29]. 38(102):593-606. Disponível em: http://www.scielo.br/scielo.php?script=sci_arttext \&pid=S0103-11042014000300593\&lng=en.

10. Pelbart PP. A nau do tempo-rei: sete ensaios sobre o tempo da loucura. Rio de Janeiro: Imago; 1993.

11. Pande MNR, Amarante P. Desafios para os Centros de Atenção Psicossocial como serviços substitutivos: a nova cronicidade em questão. Cien Saude Colet 2011; 16(4):2067-2076.

12. Passos E, Kastrup V. Sobre a validação da pesquisa cartográfica: acesso à experiência, consistência e produção de efeitos. Fractal Rev Psicol 2013; 25(2):391-413.

13. Passos E, Barros RB. A cartografia como método de pesquisa-intervenção. In: Passos E, Kastrup V, Escossia L, organizadores. Pistas do Método da Cartografia: Pesquisa-Intervenção e Produção de Subjetividade. Porto Alegre: Sulina; 2015. p. 17-31.

14. Alvarez J, Passos E. Cartografar é habitar um território existencial. In: Passos E, Kastrup V, Escossia L, organizadores. Pistas do Método da Cartografia: Pesquisa-Intervenção e Produção de Subjetividade. Porto Alegre: Sulina; 2015. p. 131-149.

15. Rolnik S. Cartografia Sentimental: Transformações contemporâneas do desejo. São Paulo: Estação Liberdade; 1989.

16. Brasil. Ministério da Saúde (MS). Política Nacional de Atenção Básica. Brasília: MS; 2012.
17. Renault L, Passos E, Silva A. Da entrevista de explicitação à entrevista na pesquisa cartográfica. In: Amador FS, Barros MEB, Fonseca TMG, organizadores. Clínicas do Trabalho e Paradigma Estético. Porto Alegre: UFRGS; 2016. p. 61-77.

18. Augusto DM, Feitosa MZS, Bomfim ZAC. A utilização dos mapas afetivos como possibilidade de leitura do território no CRAS. Est Inter em Psicol 2016; 7(1):145158.

19. Trecho 2.8. O Projeto. [acessado 2018 nov 15]. Disponível em: http://www.trecho2ponto8.com/sobre.

20. Machado K. O racismo em três séculos de escravidão. EPSJV/Fiocruz; [acessado 2020 out 19]. 2018 Maio 11. Disponível em: http://www.epsjv.fiocruz.br/noticias/ reportagem/o-racismo-em-tres-seculos-de-escravidao.

21. Deleuze G, Guattari F. Mil Platôs. Capitalismo e Esquizofrenia. Rio de Janeiro: Editora 34; 1980.

22. Merhy EE, Gomes MPC, Silva E, Santos MFL, Cruz KT, Franco TB. Redes Vivas: multiplicidades girando as existências, sinais da rua. Implicações para a produção do cuidado e a produção do conhecimento em saúde. Divulg Saude Debate 2014; (52):153-164.

23. Carvalho MN, Franco TB. Cartografia dos caminhos de um usuário de serviços de saúde mental: produção de si e da cidade para desinstitucionalizar. Physis 2015; 25(3):863-884

24. Saraceno B. Libertando Identidades. Da reabilitação psicossocial à cidadania possivel. Belo Horizonte: Te Corá Editora; 1999.

25. Yasui S. A produção do cuidado no território: "há tanta vida lá fora". Textos de apoio do Ministério da Saúde. Brasília: Ministério da Saúde; 2011.

26. Pelbart PP. Da Polinização em Filosofia. In: $O$ avesso do niilismo: cartografias do esgotamento. São Paulo: N-1 Edições; 2013. p. 371-387.

Artigo apresentado em 31/10/2020

Aprovado em 14/10/2021

Versão final apresentada em 16/10/2021

Editores-chefes: Romeu Gomes, Antônio Augusto Moura da Silva 
